Pesq. Vet. Bras. 38(1):99-106, janeiro 2018 DOI: $10.1590 / \mathrm{S} 0100-736 \mathrm{X} 2018000100016$

\title{
Características epidemiológicas, clínico-patológicas e morfotintoriais de quatorze casos de nocardiose em cães ${ }^{1}$
}

\author{
Maria T.S. Frade ${ }^{2 *}$, Millena de O. Firmino ${ }^{2}$, Lisanka A. Maia ${ }^{2}$, Aline M. Silveira², \\ Maria J.R. do Nascimento ${ }^{3}$, Francisco S. de M. Martins ${ }^{4}$, Almir P. de Souza ${ }^{5}$ \\ e Antônio F.M. Dantas ${ }^{5}$
}

\begin{abstract}
Frade M.T.S., Firmino M.O., Maia L.A., Silveira A.M., Nascimento M.J.R., Martins F.S.M., Souza A.P. \& Dantas A.F.M. 2018. [Epidemiological, clinical, pathological and morphotinctorial features of fourteen cases of nocardiosis in dogs.] Características epidemiológicas, clínico-patológicas e morfotintoriais de quatorze casos de nocardiose em cães. Pesquisa Veterinária Brasileira 38(1):99-106. Laboratório de Patologia Animal, Hospital Veterinário, Centro de Saúde e Tecnologia Rural, Universidade Federal de Campina Grande, Campus de Patos, Avenida Universitária s/n, Bairro Santa Cecília, Patos, PB 58708110, Brazil. E-mail: talita_frade@hotmail.com.br

This paper describes the epidemiological, clinical, pathological and morphotinctorial characteristics in fourteen cases of nocardiosis in dogs. A retrospective study for the period of January 2005 to December 2015 was made and selected suggestive cases of nocardiosis. The identification and characterization of the agent was performed by special histochemical techniques Methenamine silver nitrate Grocott (GMS), modified Ziehl-Neelsen, Gram stain type modified Brown-Brenn and Giemsa. Were affected predominantly young and in twelve cases were associated with canine distemper virus (CDV). Clinical signs vary from respiratory, neurological and skin changes, mainly related to concomitant infection by CDV. Macroscopically had multifocal areas coalescing, yellowish-white, firm, elevated in surface and deepened the court, sometimes with purulent material, intermixed by irregular reddened areas affecting mainly lungs, lymph nodes, liver, kidneys, and brain. The cutaneous lesions were predominantly observed in cervical and inguinal and ranged from suppurative well as pyogranulomatous. In the histopathologic examination the injury was mainly characterized by inflammation pyogranulomatous, but in some areas there was a predominance of necrossupurativa inflammation, epithelioid macrophages and were frequently observed, forming clusters radiated form, often reminding rosettes. In the histochemical techniques were observed filamentous structures, branched, non-septate, measuring approximately $1 \mu \mathrm{m}$ thick, impregnated on silver staining, stained in red on the modified Ziehl-Neelsen, in blue on Gram stain type modified Brown-Brenn and weakly pale pink in Giemsa. The nocardiosis should be considered in young animals with progressive respiratory and neurological signs, as well as skin lesions involving the subcutaneous tissue and regional lymph nodes. It should be further investigated a possible predisposing factor, such as infection by canine distemper virus and hemoparasites. The diagnosis was established by histopathological examination based on the morphology of the bacteria and their histochemical characteristics,
\end{abstract}

\footnotetext{
${ }^{1}$ Recebido em 24 de maio de 2016.

Aceito para publicação em 11 de janeiro de 2017.

${ }^{2}$ Discente do Programa de Pós-Graduação em Medicina Veterinária, Centro de Saúde e Tecnologia Rural (CSTR), Universidade Federal de Campina Grande (UFCG), Avenida Universitária s/n, Bairro Santa Cecília, Patos, PB 58708-110, Brasil. *Autor para correspondência: talita_frade@ hotmail.com

${ }^{3}$ Graduação em Medicina Veterinária, Centro de Saúde e Tecnologia
}

Rural (CSTR), Universidade Federal de Campina Grande (UFCG), Avenida Universitária s/n, Bairro Santa Cecília, Patos, PB 58708-110, Brasil.

${ }^{4}$ Programa em Residência Multiprofissional da Saúde, Hospital Veterinário, CSTR-UFCG, Avenida Universitária s/n, Bairro Santa Cecília, Patos, PB 58708-110, Brasil.

${ }^{5}$ Docente do Programa de Pós-Graduação em Medicina Veterinária, CSTR-UFCG, Avenida Universitária s/n, Bairro Santa Cecília, Patos, PB 58708-110, Brasil. 
distinguishing mainly from other bacterial and fungal agents and is an important tool for the diagnosis, when the collection of material for cultivation and isolation of the agent is not possible.

INDEX TERMS: Nocardiosis, dogs, Nocardia sp., bacterioses, immunosuppression.

RESUMO.- Este artigo descreve os aspectos epidemiológicos, clínicos, patológicos e características morfotintoriais em quatorze casos de nocardiose em cães. Para isso foi realizado um estudo retrospectivo durante o período de janeiro de 2005 a dezembro de 2015 e selecionados os casos sugestivos de nocardiose. A identificação e caracterização do agente foi realizada através de técnicas histoquímicas especiais de Metenamina nitrato de prata de Grocott (GMS), Ziehl-Neelsen modificado, coloração de Gram do tipo Brown-Brenn modificado e Giemsa. Foram afetados predominantemente filhotes e em doze casos havia associação com o vírus da cinomose canina (VCC). Os sinais clínicos variaram de alterações respiratórias, neurológicas e cutâneas, relacionadas principalmente à infecção concomitante pelo VCC. Macroscopicamente haviam áreas multifocais a coalescentes, branco-amareladas, firmes, elevadas na superfície e que se aprofundavam ao corte, por vezes com material purulento, entremeadas por áreas avermelhadas irregulares afetando principalmente pulmões, linfonodos, fígado, rins e encéfalo. As lesões cutâneas foram observadas predominantemente nas regiões cervical e inguinal e variaram de supurativas a piogranulomatosas. No exame histopatológico a lesão era caracterizada principalmente por inflamação piogranulomatosa, porém em algumas áreas havia predomínio de inflamação necrossupurativa, e frequentemente eram observados macrófagos epitelioides, formando aglomerados de forma radiada, muitas vezes lembrando pseudorosetas. Nas técnicas histoquímicas foram observadas estruturas filamentosas, ramificadas, não septadas, medindo aproximadamente $1 \mu \mathrm{m}$ de espessura, impregnadas na coloração de prata, coradas em vermelho no Ziehl-Neelsen modificado, em azul na coloração de Gram do tipo Brown-Brenn modificado e fracamente rósea pálido no Giemsa. A nocardiose deve ser considerada em animais jovens que apresentam sinais respiratórios e neurológicos progressivos, bem como em lesões cutâneas com envolvimento do subcutâneo e linfonodos regionais. Deve ser investigado ainda um provável fator predisponente, como a infecção pelo vírus da cinomose canina e hemoparasitoses. 0 diagnóstico foi estabelecido através do exame histopatológico baseando-se na morfologia da bactéria e suas características histoquímicas, distinguindo principalmente de outros agentes bacterianos e fúngicos, constituindo uma importante ferramenta para o diagnóstico, quando não é possível a coleta do material para cultivo e isolamento do agente.

TERMOS DE INDEXAÇÃO: Nocardiose, cães, Nocardia sp., infecções oportunistas, imunossupressão, bacterioses.

\section{INTRODUÇÃO}

0 gênero Nocardia consiste em bactérias aeróbicas, gram-positivas, parcialmente álcool-ácido resistentes, filamentosas e ramificadas (Beaman \& Beaman 1994). São microrganismos ubíquos encontrados no solo, na água, em vegetais, em matéria orgânica em decomposição, poeira, vegetais e matéria fecal (Sykes 2015). A rota de infecção ocorre através da inalação de aerossóis, ingestão, contato com ambiente contaminado com o agente (Beaman \& Sugar 1983) ou pela inoculação percutânea através de traumas (Sykes 2015).

As infecções nos animais e no homem são caracterizadas por lesões supurativas a granulomatosas com evolução crônica e difícil resolução terapêutica (Beaman \& Beaman 1994). Em animais de companhia as principais manifestações clínicas são lesões tegumentares (cutâneas/subcutâneas) e pulmonares (Kirpensteijn \& Fingland 1992).

A nocardiose afeta principalmente indivíduos imunocomprometidos (Sykes 2015, Ribeiro \& Condas 2016). Nos cães geralmente está associada à infecção pelo vírus da cinomose canina (VCC) (Fawi et al. 1971, Ribeiro et al. 2002, 2008), mas também pode estar associada ao uso prolongado de drogas imunossupressivas, como a ciclosporina (Smith et al. 2007, MacNeill et al. 2010, Hilligas et al. 2014) e corticoides, assim como ao estresse (Kinch 1968). Apesar do comportamento oportunista do agente, nem todos os animais apresentam relação direta com fatores imunossupressivos (Marino \& Jaggy 1993, Ribeiro \& Condas 2016).

Em cães, as lesões disseminadas de nocardiose nos pulmões e no sistema nervoso central (SNC), têm sido associadas à infecção por Nocardia asteroides (Fawi et al. 1971, Marino \& Jaggy 1993). Nos casos com lesões cutâneas há predominantemente a ocorrência de $N$. brasiliensis (Marino \& Jaggy 1993, Beaman \& Beaman 1994). Também tem sido relatado caso de infecção por $N$. pseudobrasiliensis causando osteomielite vertebral e lesões cutâneas múltiplas (Hilligas et al. 2014).

No Brasil, um estudo realizado por Ribeiro et al. (2008), demonstrou que a espécie mais frequentemente diagnosticada nas lesões cutâneas foi $N$. otitidiscaviarum, mas também foi encontrado um caso de $N$. asteroides das lesões cutâneas e em um caso de lesão pulmonar foi isolado $N$. nova.

O diagnóstico de nocardiose pode ser feito através do histórico, sinais clínicos, exames hematológicos, microbiológico, anatomopatológico e molecular (Ribeiro et al. 2002). Porém, é importante ressaltar que infecções bacterianas podem variar quanto o aspecto macroscópico da lesão, dificultando o diagnóstico presuntivo e coleta de material para cultivo e isolamento. Nesses casos o exame histopatológico tem demonstrado ser uma importante ferramenta para o diagnóstico, baseando-se nas características morfológicas da lesão e do agente, assim como suas propriedades histoquímicas.

Desta forma, objetivou-se com este trabalho, descrever quatorze casos de nocardiose em cães, abordando os aspectos epidemiológicos, clínicos, patológicos e características morfotintoriais do agente. 


\section{MATERIAL E MÉTODOS}

Foram revisadas as fichas de necropsias de cães e selecionados os casos sugestivos de nocardiose diagnosticados no Laboratório de Patologia Animal da Universidade Federal de Campina Grande (UFCG) durante o período de janeiro de 2005 a dezembro de 2015. Avaliaram-se os dados epidemiológicos (raça, sexo, idade, procedência do animal, estado vacinal e ocorrência de doenças concomitantes ou tratamentos anteriores), os sinais clínicos, lesões macroscópicas e histológicas, descritos nos protocolos de necropsias. Para mais detalhamento dos dados epidemiológicos e dos sinais clínicos foram revisadas as fichas clínicas de atendimento referentes a esses animais nos arquivos da Clínica Médica de Pequenos Animais (CMPA).

Os fragmentos provenientes de necropsias haviam sido fixados em formol a $10 \%$ e processados rotineiramente para his- topatologia. As secções histológicas coradas pela hematoxilina e eosina (HE) foram avaliadas visando caracterizar a resposta inflamatória de cada caso. Posteriormente, foram realizadas as técnicas histoquímicas de Metenamina nitrato de prata de Grocott (GMS), Ziehl-Neelsen modificado, coloração de Gram do tipo Brown-Brenn modificado e Giemsa para visualização do agente.

\section{RESULTADOS}

Durante o período estudado foram necropsiados 1.283 cães, e desses foram diagnosticados 14 casos de nocardiose, representando $1,1 \%$ das causas de morte e/ou eutanásia. Destes 14 casos de nocardiose diagnosticados oito $(57,1 \%)$ eram fêmeas, sendo cinco sem raça definida (SRD) e as demais eram das raças Poodle, Pit bull e Golden retrie-

Quadro 1. Características epidemiológicas, clínicas, doenças concomitantes e distribuição das lesões em cães com nocardiose diagnosticados de janeiro/2005 a dezembro/2015 no Laboratório de Patologia Animal da Universidade Federal de Campina Grande, Patos, PB

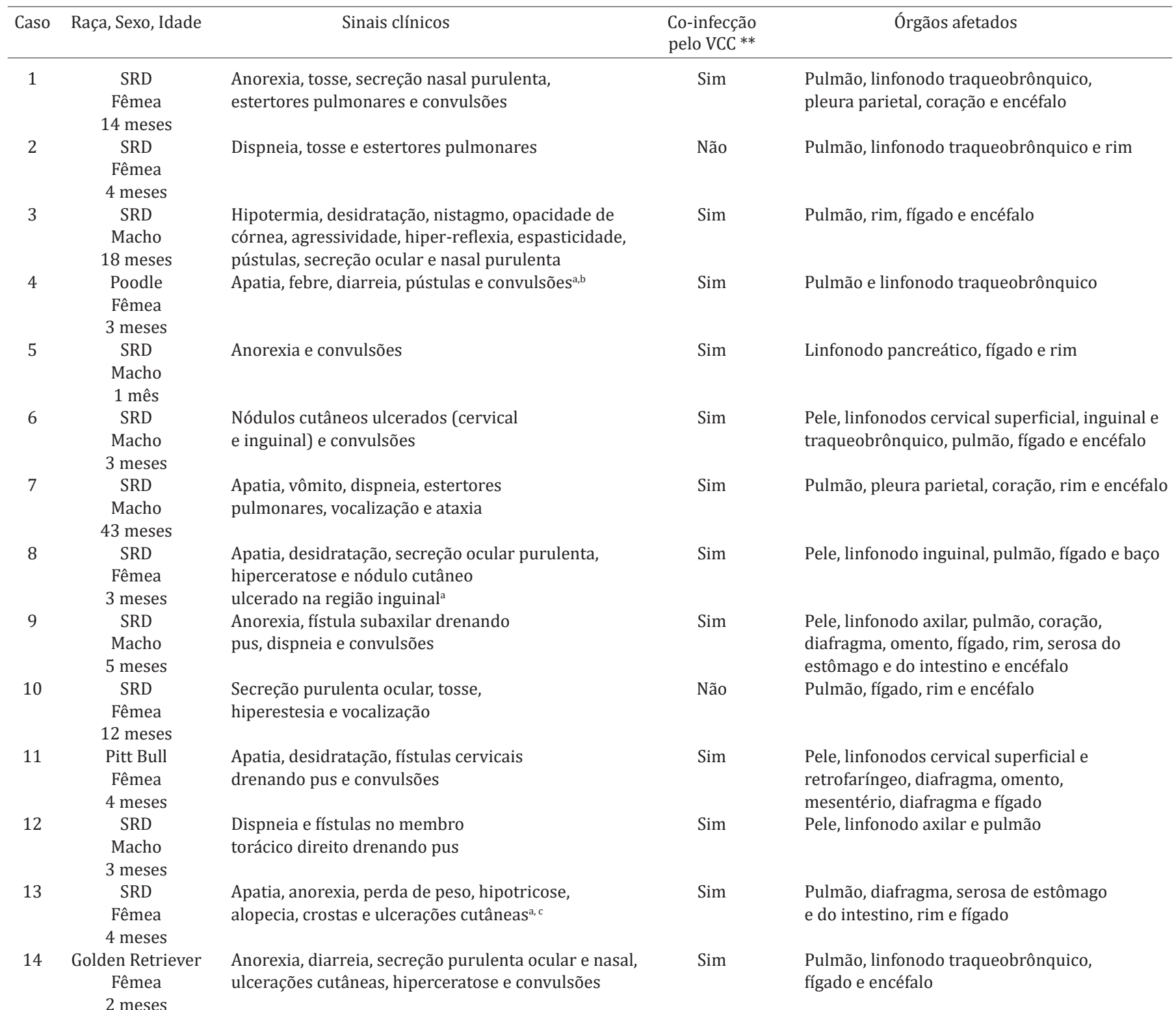

\footnotetext{
*SRD = Sem raça definida, ${ }^{* *}$ VCC = vírus da cinomose canina, diagnóstico pela presença de inclusões nos tecidos corados pela HE; a animal com erliquiose,

${ }^{\mathrm{b}}$ animal com babesiose, ${ }^{\mathrm{c}}$ animal com demodicose.
} 
ver, e seis $(42,9 \%)$ eram machos todos SRD. A idade dos animas afetados variou de um mês a três anos e sete meses, com ocorrência da doença predominantemente em filhotes, representado por $79 \%$ dos casos $(11 / 14)$, em sua maioria até três meses de idade (6/11). Os dados epidemiológicos, clínicos, doenças concomitantes e a localização das lesões encontram-se no Quadro 1.

Doze animais eram domiciliados e/ou peridomiciliados, um caso era animal de rua (Caso 13) e um era proveniente da zona rural (Caso 8). Sete cães apresentavam carrapatos (Casos 2, 3, 4, 7, 8, 9 e 14). Os diagnósticos de erliquiose e babesiose foram realizados pelo hemograma e pesquisa de hemoparasitas. Nesses casos foi instituído tratamento para essas hemoparasitoses.

O estado vacinal foi informado em seis casos, desses, três animais não eram vacinados (Casos 3, 7 e 13) e três tinham vacinação incompleta (Casos 4, 8 e 14).

Os sinais clínicos descritos foram inespecíficos e variaram de acordo com a localização das lesões, caracterizados principalmente por alterações respiratórias, neurológicas e cutâneas, relacionadas principalmente à infecção concomitante pelo vírus da cinomose canina.

As manifestações respiratórias foram observadas em $57 \%$ dos casos, caracterizadas por tosse $(3 / 14)$, secreção nasal (3/14), estertores pulmonares $(3 / 14)$ e dispneia $(4 / 14)$. Os sinais neurológicos estiveram presentes em $71 \%$ dos casos $(10 / 14)$. Destes, o mais frequente foi a convulsão $(7 / 10)$. Os animais apresentaram também vocalização $(2 / 10)$, hiper-reflexia $(2 / 10)$, nistagmo $(1 / 10)$, agressividade $(1 / 10)$, espasticidade $(1 / 10)$ e ataxia $(1 / 10)$. As lesões cutâneas foram relatadas em $36 \%$ dos casos e apresentaram-se na forma de fístulas (3/14) e nódulos (2/14). Outros sinais comumente descritos foram apatia $(5 / 14)$, anorexia $(5 / 14)$, desidratação $(2 / 14)$, pústulas $(2 / 14)$ e hiperceratose $(2 / 14)$.

As lesões macroscópicas associadas à infecção por Nocardia sp. foram observadas predominantemente no sistema respiratório, afetando principalmente os pulmões $(12 / 14)$. Em seis casos com lesões pulmonares, os animais não apresentaram manifestações clínicas respiratórias (Casos 4, 6, 8, 9, 12 e 13). Havia comprometimento de linfonodos próximo aos prováveis locais de lesões primárias, os linfonodos mais afetados foram traqueobrônquicos (5/14), seguidos dos linfonodos cervicais superficiais $(2 / 14)$, inguinais $(2 / 14)$, axilares $(2 / 14)$, retrofaríngeo $(1 / 14)$ e pancreático (1/14).

A disseminação das lesões pulmonares ou cutâneas afetou principalmente o fígado principalmente o fígado $(8 / 14)$, encéfalo $(7 / 14)$, rins $(6 / 14)$ e ocasionalmente o diafragma $(4 / 14)$, coração $(3 / 14)$, intestino $(2 / 14)$, estômago $(2 / 14)$, omento (2/14), pâncreas (1/14) e baço (1/14).

As lesões cutâneas variavam de massas multinodulares a lesões ulceradas e supurativas. No Caso 6 observou-se massa multinodular, firme, elevada com superfície ulcerada, localizada na região cervical com $9,0 \times 7,5 \times 5,0 \mathrm{~cm}$ de extensão e na região inguinal medindo $3,0 \mathrm{~cm}$ de diâmetro. Caso 8 havia massa na região inguinal medindo $8,0 \times 7,0 \times 4,0 \mathrm{~cm}$ de extensão, superfície avermelhada ulcerada e bordos irregulares elevados (Fig.1A), com suspeita clí- nica de neoplasia mamária devido ao aumento de volume na região próximo a mama inguinal direita. Casos 9, 11 e 12 a lesão apresentava-se ulcerada com bordos irregulares que se estendia ao subcutâneo e musculatura adjacente, formando tratos fistulosos (Fig.1B), por vezes com coleção de pus (flegmão), drenando secreção purulenta. No Caso 12 a secreção apresentava-se ainda sanguinolenta. Presença de líquido serossanguinolento com aspecto de "molho de tomate" (Fig.1C) foi observado na cavidade torácica em dois casos (Casos 1 e 7) e na cavidade abdominal em um caso, que também apresentava deposição de fibrina no peritônio e diafragma (Caso 13).

Havia envolvimento de linfonodos profundos em $42 \%$ $(6 / 14)$ e superficiais em 35\% (5/14) dos casos. Os linfonodos regionais próximos as áreas de lesão foram os mais afetados e apresentavam-se aumentados de volume com superfície irregular e ao corte haviam áreas multifocais amareladas e firmes entremeadas por áreas esbranquiçadas que drenavam secreção purulenta (Fig.1D).

Os demais órgãos afetados nas cavidades torácica e abdominal apresentavam áreas multifocais a coalescentes, branco-amareladas, firmes e elevadas que adentravam o parênquima dos órgãos. A superfície de corte apresentava-se com áreas avermelhadas e irregulares com material purulento (Fig.1E). No SNC, após a fixação e realização de cortes transversais, observaram-se áreas nodulares focais, multifocais e multifocais a coalescente, branco-amareladas em três casos (Casos 6, 7 e 10). Caso 9 observaram-se áreas multifocais vermelho-acinzentadas na substância cinzenta do córtex parietal (Fig.1F) e áreas de rarefação em núcleos da base. Caso 14 o ventrículo lateral direito estava preenchido por conteúdo gelatinoso e translúcido.

Microscopicamente a lesão era caracterizada principalmente por inflamação piogranulomatosa (Fig.2A), mas em algumas áreas havia predomínio de inflamação necrossupurativa. Observavam-se áreas multifocais a coalescentes compostas por infiltrado inflamatório, caracterizado por áreas centrais de necrose com neutrófilos íntegros e degenerados, circundados por macrófagos epitelioides, formando aglomerados de forma radiada semelhante à pseudorosetas (Fig.2B). A intensidade da resposta inflamatória variou de moderada a acentuada. Na periferia das áreas de inflamação, com exceção do SNC, havia proliferação de tecido conjuntivo fibroso associado a ocasionais linfócitos, plasmócitos e células gigantes multinucleadas.

No SNC as lesões microscópicas estavam presentes em $50 \%$ dos casos (7/14). A distribuição da lesão era variável e afetava principalmente a substância cinzenta dos córtices frontal, parietal, temporal e occipital, mas também havia envolvimento de núcleos da base, tálamo, cerebelo, ponte, lobo piriforme, colículo caudal, medula, meninges e espaços periventriculares. Desses sete casos com lesões características de Nocardia no SNC, em quatro havia apenas lesão de origem bacteriana (Casos 3, 7, 10 e 14) e em três deles além da lesão bacteriana, havia também lesões características de infecção pelo vírus da cinomose canina (Casos 1, 6 e 9). Em três casos (3/10) em que as lesões características de Nocardia estiveram ausentes, os sinais neurológicos foram relacionados apenas a infecção pelo VCC (Casos 4, 5 e 11). 
O agente etiológico foi visualizado nas secções histológicas coradas pelas técnicas histoquímicas de Metenamina nitrato de prata de Grocott, Ziehl-Neelsen modificado, co- loração de Gram tipo Brown-Brenn modificado e Giemsa. Em todos os casos foram observados estruturas filamentosas, ramificadas, não septadas, com aproximadamente 1
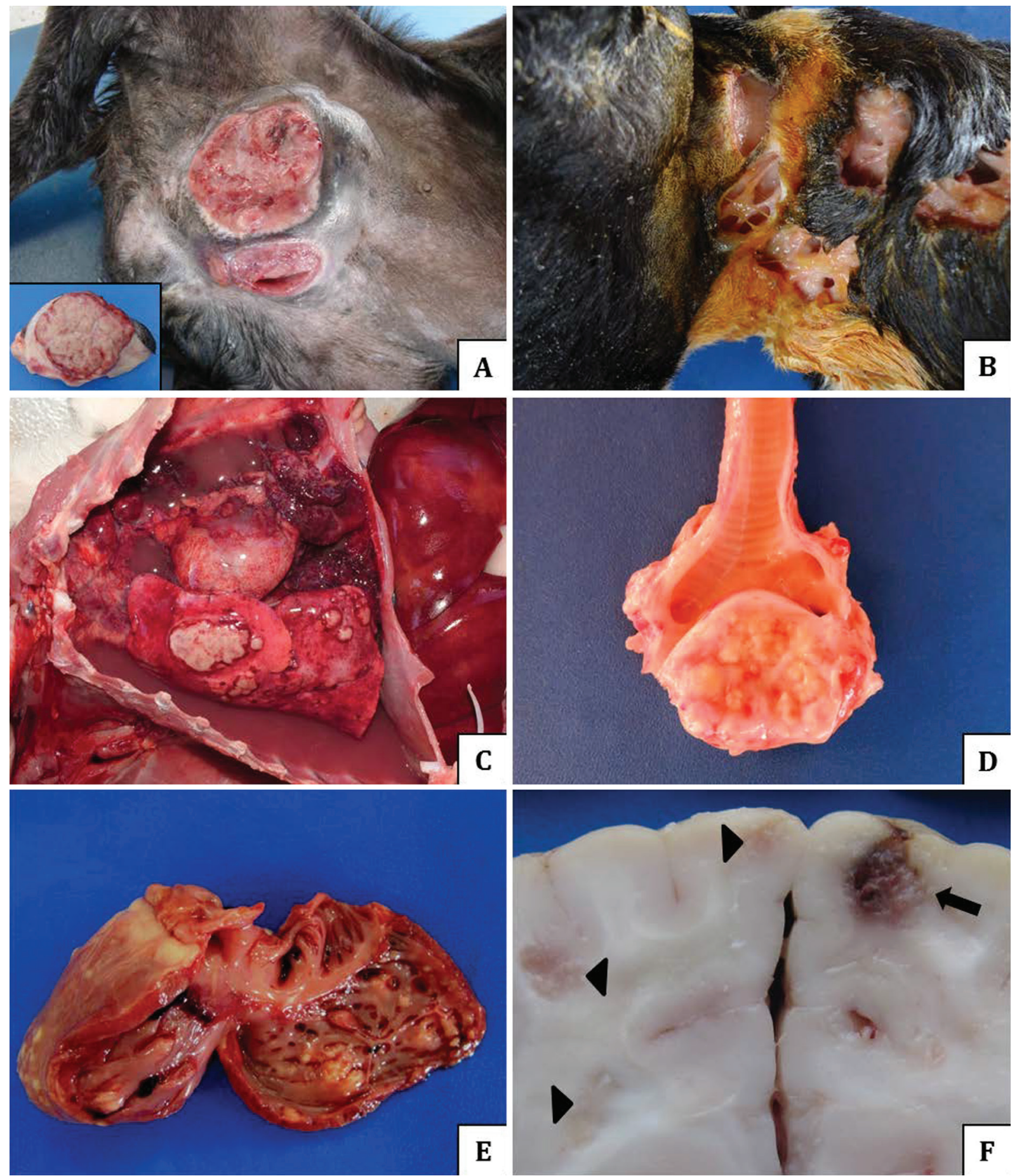

Fig.1. Nocardiose em cães. (A) Pele da região inguinal direita com nódulos ulcerados de superfície avermelhada e irregular. No detalhe: superfície de corte com áreas branco-acinzentadas que se estendem ao tecido subcutâneo. (B) Pele da região cervical com áreas multifocais ulceradas irregulares formando tratos fistulosos com secreção purulenta. (C) Cavidade torácica com acúmulo de líquido avermelhado e viscoso com aspecto semelhante a "molho de tomate" e áreas multifocais a coalescentes amarelas e elevadas circundadas por um halo avermelhado no parênquima dos lobos pulmonares direito. (D) Linfonodo traqueobrônquico com áreas multifocais a coalescentes amareladas entremeadas por áreas esbranquiçadas e perda da arquitetura do órgão. (E) Coração com nódulos multifocais branco-amarelados e elevados na superfície epicárdica do ventrículo esquerdo e endocárdica do ventrículo direito. (F) Encéfalo. Área focal vermelho-acinzentada predominantemente na substância cinzenta do córtex parietal direito (seta) e múltiplas áreas de rarefação nas substâncias cinzenta e branca do córtex parietal esquerdo (cabeças de seta). 
$\mu \mathrm{m}$ de espessura, impregnadas pela prata (Fig.2C), coradas em vermelho (Fig.2D), em azul (Fig.2E) e fracamente rósea pálido (Fig.2F), respectivamente, compatíveis com infecção bacteriana pelo gênero Nocardia. As bactérias eram visualizadas principalmente na periferia dos piogranulomas, no centro das pseudorosetas, no citoplasma de macrófagos e células epitelioides, mas também observadas nas áreas de necrose.

A cinomose foi confirmada pelo exame histopatológico em $85,7 \%$ dos casos. As lesões histológicas compatíveis com cinomose eram caracterizadas por desmielinização, presença de gemistócitos e corpúsculos de inclusões eo-
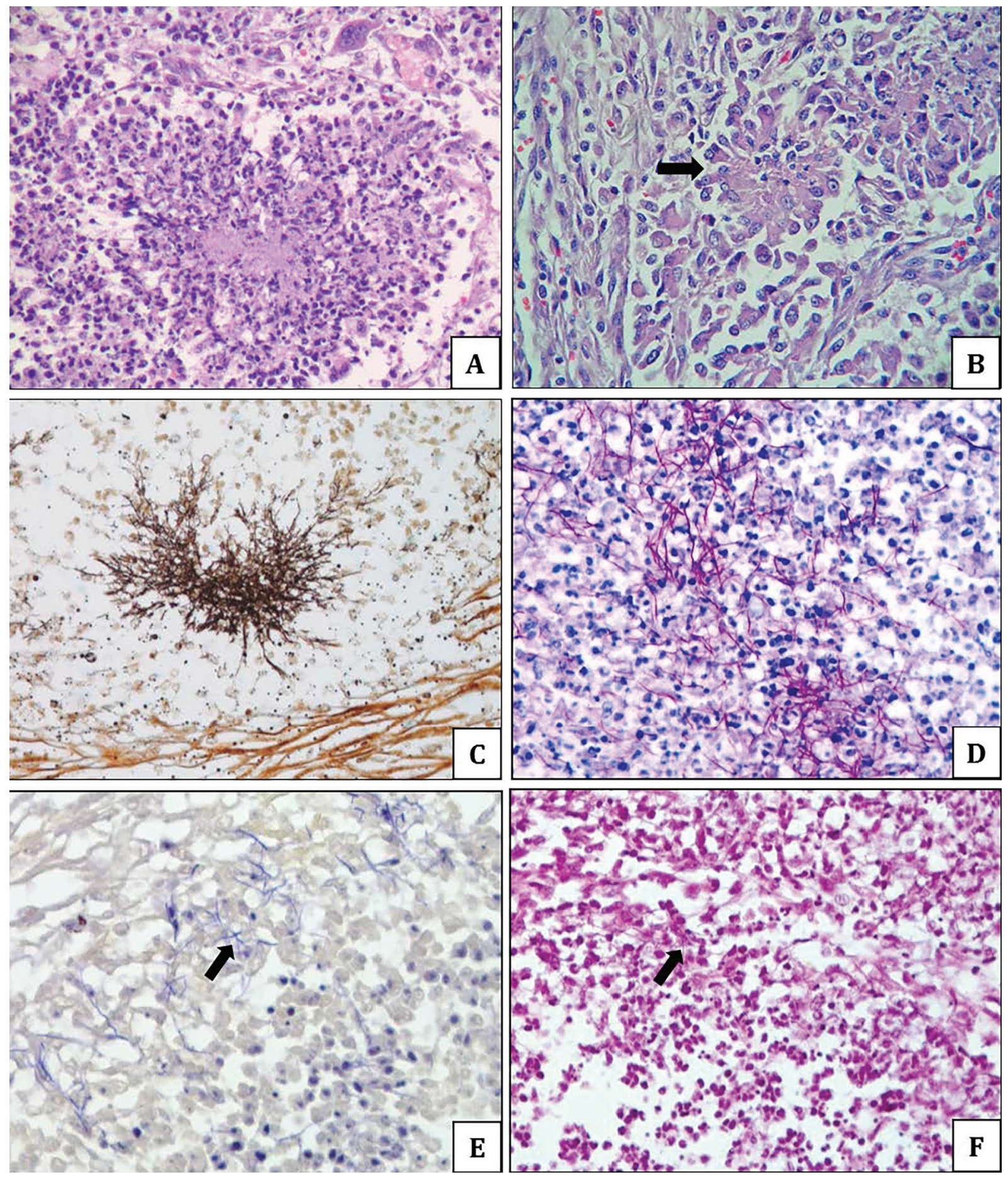

Fig.2. Nocardiose em cães. (A) Pele com área de necrose e com neutrófilos predominantemente degenerados, circundados por macrófagos epitelioides. HE, obj.20x. (B) Linfonodo com aglomerados de macrófagos epitelioides formando pseudorosetas (seta). HE, obj.20x. (C) Baço com emaranhado de estruturas filamentosas, ramificadas, não septadas fortemente impregnadas pela prata, características de Nocardia sp. GMS, obj.40x. (D-F) Pulmão com evidenciação de Nocardia sp. apresentando-se como estruturas filamentosas coradas em vermelho pelo Ziehl-Neelsen modificado (D), azul (seta) pela coloração de Gram do tipo Brown-Brenn modificado (E), e rósea (seta) pelo Giemsa (F); obj.40x. 
sinofílicos intracitoplasmáticos e/ou intranucleares em astrócitos e células ependimárias (Casos 1, 4, 5, 6, 9 e 11). Corpúsculos de inclusão também foram observados em órgãos extraneurais em células parietais, principais e prismáticas da mucosa gástrica, células epiteliais da mucosa da bexiga, brônquios, bronquíolos e pelve renal (Casos 1, 3, 4, $5,6,7,8,12,13$ e 14).

O diagnóstico de demodicose no Caso 13 foi estabelecido pelo exame histopatológico através da visualização de ácaros alongados com exoesqueleto quitinoso fino e eosinofílico, apêndices articulados curtos, uma hemocele, músculo estriado, e tratos digestivo e reprodutor em folículos pilosos compatíveis com Demodex sp. No Caso 8 com suspeita de neoplasia mamária foi confirmada a infecção bacteriana.

\section{DISCUSSÃO}

O diagnóstico de nocardiose nesses quatorzes casos foi baseado nos aspectos macro e microscópicos das lesões e através da visualização do agente e suas características morfotintoriais.

Com base nos dados epidemiológicos e principalmente quadro clínico de sinais neurológicos, a cinomose foi considerada como doença primária na maioria dos casos, confirmada através do exame histopatológico. Em um estudo realizado por Ribeiro et al. (2008) a co-infecção com o vírus da cinomose esteve presente em 55\% dos casos de nocardiose, constituindo um importante fator que predispõe a essa infecção (Fawi et al. 1971).

A ocorrência da doença predominantemente em filhotes foi relacionada ao período de maior susceptibilidade a infecção pelo VCC. Os filhotes tornam-se mais susceptíveis a cinomose quando a imunidade materna conferida diminui (Appel \& Summers 1995). Desta forma, a maior ocorrência em filhotes está relacionada a diversos fatores como falhas na transferência passiva, baixa adesão aos programas de vacinação, administração incorreta da vacina em imunossuprimidos ou protegidos de forma passiva, animais que não respondem quando a vacina é administrada tardiamente em animais já infectados e a utilização de vacinas mal armazenadas (Fighera et al. 2008, Tizard 2014).

Além da infecção pelo VCC, outras enfermidades podem ter contribuído para uma imunossupressão desses animais, como as hemoparasitoses. Acredita-se que outros fatores de risco para à ocorrência de nocardiose em cães estejam relacionados às falhas no manejo nutricional, de higienização e profilático, submetendo-os a inadequados protocolos de vacinação, desverminação e sem efetivo controle de ectoparasitas.

A ocorrência de doenças associadas e sinais clínicos inespecíficos podem mascarar e dificultar um diagnóstico clínico presuntivo de nocardiose (Marino \& Jaggy 1993). A maioria dos estudos reportam a nocardiose predominantemente como lesões cutâneo-subcutâneas, e menos frequentemente lesões pulmonares, ou disseminadas incluindo o SNC (Ribeiro et al. 2008, Ribeiro \& Condas 2016). Diferente desses relatos, neste estudo as lesões foram predominantes no sistema respiratório e comumente havia o envolvimento do SNC. Acredita-se que a via de infecção mais importante foi à respiratória, devido ao maior número de animais com lesões no trato respiratório, seguida pelas lesões cutâneas, com disseminação sistêmica a partir dessas lesões primárias. Apesar de apresentar maior importância para animais de produção (Côrrea et al. 1973), a via digestória foi considerada em um caso, tendo em vista a ausência de lesões cutâneas e pulmonares e a predominância de lesões em órgãos anexos ao sistema digestório. Em apenas um caso a lesão ficou restrita ao sistema respiratório, constituindo a forma pulmonar da doença, mais comumente relatada em humanos (Sykes 2015).

Embora a ocorrência de sinais neurológicos na nocardiose seja considerada incomum (Beaman \& Sugar 1983), neste estudo foi observado em mais da metade dos casos. A convulsão foi a manifestação neurológica mais frequente neste estudo, apesar de estar entre os sinais clínicos mais comuns da cinomose, ficando atrás das mioclonias e da incoordenação motora (Silva et al. 2007), esteve presente nos casos em que a lesão no SNC pelo vírus estiveram ausentes.

As lesões cutâneas foram observadas mais comumente nas regiões cervical e inguinal, semelhante ao encontrado por Ribeiro et al. (2002), que podem apresentar-se na forma de abscessos, nódulos, úlceras e linfadenopatia, podendo ainda fistular e drenar conteúdo purulento (Ribeiro \& Condas 2016).

A presença de líquido com aspecto de "molho de tomate" é comumente encontrada em infecções por actinomicetos, sendo Nocardia asteroides e Actinomyces sp. importantes causas de efusões pleurais e peritoneais (Raskin \& Meyer 2011). Entretanto, em casos de actinomicose comumente observam-se "grânulos de enxofre" (Marino \& Jaggy 1993), que não foram observados em nenhum caso desse estudo.

Classicamente as infecções por espécies do gênero Nocardia em animais induzem a reações piogranulomatosas de difícil resolução tecidual, com tendência ao desenvolvimento de processos inflamatórios de evolução crônica (Ribeiro \& Condas 2016). A característica da reação inflamatória e o arranjo celular foram determinantes para o diagnóstico, principalmente a presença dos macrófagos epitelioides distribuídos de forma radiada, semelhante a pseudorosetas, compatíveis com a infecção por Nocardia.

Nas colorações especiais de Giemsa e GMS, a visualização de estruturas filamentosas e ramificadas coradas podem sugerir agentes fúngicos (MacNeill et al. 2010), porém em contraste com os fungos, Nocardia apresenta espessura relativamente fina, variando de 0.5 a $2.0 \mu \mathrm{m}$ (MacNeill et al. 2010, Raskin \& Meyer 2011, Ribeiro \& Condas 2016). Outra característica morfotintorial importante que permite identificar o gênero Nocardia, está relacionada à presença de ácido micólico na sua parede, que confere a característica desses microrganismos serem parcialmente álcool-ácido resistentes (Ribeiro \& Condas 2016), sendo vistos como grandes grupos de agregados frouxos e emaranhados pela coloração de Ziehl-Neelsen modificado (Sykes 2015, Ribeiro \& Condas 2016) e também pelo Gram.

Morfologicamente Nocardia e Actinomyces são semelhantes, no entanto em colorações especiais Actinomyces é impregnada pela prata (GMS) e Gram positivo, porém não é álcool-ácido resistente (Raskin \& Meyer 2011, Sykes 2015, Ribeiro \& Condas 2016). 
Diferentemente dos casos de infecção por Nocardia, os casos de Actinomyces apresentam fenômeno de Splendore-Hoeppli em tecidos corados pela hematoxilina e eosina, que nem sempre são observados em infecções por Nocardia (Sykes 2015). Nocardia spp. possui uma tendência limitada para se aglomerar, desta forma ela não forma tipicamente grânulos (Hargis \& Ginn 2013), sendo os grânulos mais comumente observados em lesões cutâneas (Sykes 2015).

Deve-se incluir também no diagnóstico diferencial outros gêneros de actinomicetos, como Mycobacterium. Entretanto, nesses casos bactérias desse gênero são vistas como bacilos não corados pelo Giemsa e são álcool-ácido resistentes tanto pelo Ziehl-Neelsen como pelo Ziehl-Neelsen modificado (Raskin \& Meyer 2011).

Em cães as infecções que induzem respostas necrotizantes e piogranulomatosas, como as causadas pelos protozoários Acanthamoeba sp. e Toxoplasma gondii, devem ser incluídas no diagnóstico diferencial. Entretanto esses agentes são visualizados pela hematoxilina e eosina e apresentam características morfológicas específicas (Frade et al. 2015a, 2015b).

Em nenhum caso desse estudo foi possível realizar o cultivo e o isolamento das amostras para identificação da espécie, demonstrando a importância do reconhecimento das características morfológicas e aspectos morfotintoriais para o diagnóstico de nocardiose.

O prognóstico em animais com condições imunossupressoras é desfavorável. Não existem medidas específicas para o controle e a profilaxia da nocardiose, em virtude da ampla distribuição do microrganismo no ambiente (Ribeiro \& Condas 2016). Porém a realização de vacinação periódica, vermifugação, controle de ectoparasitas, restrição ao acesso às ruas, boa alimentação e medidas de higiene do ambiente podem reduzir a instalação de processos debilitantes ou infecções com microrganismos imunossupressivos, que são fatores que podem predispor a ocorrência da doença.

\section{CONCLUSÕES}

A nocardiose deve ser considerada em cães jovens que apresentam sinais respiratórios e neurológicos progressivos, bem como em lesões cutâneas com envolvimento do subcutâneo e linfonodos regionais. Deve ser investigado ainda um provável fator predisponente, como a infecção pelo vírus da cinomose canina e hemoparasitoses.

O diagnóstico foi estabelecido através do exame histopatológico baseando-se na morfologia da bactéria e suas características histoquímicas, distinguindo principalmente de outros agentes bacterianos e fúngicos.

A histoquímica demonstra ser uma importante ferramenta para o diagnóstico, quando não é possível a coleta do material para cultivo e isolamento do agente.

\section{REFERÊNCIAS}

Appel M.J.G. \& Summers B.A. 1995. Pathogenicity of morbilliviruses for terrestrial carnivores. Vet. Microbiol. 44(2/4):187-191.

Beaman B.L. \& Sugar A.M. 1983. Nocardia in naturally acquired and experimental infections in animals. J. Hyg. 91(3):393-419.

Beaman B.L. \& Beaman L. 1994. Nocardia species: host-parasite relationships. Clin. Microbiol. Rev. 7(2):213-264.

Corrêa C.N.M., Corrêa W.M., Gottschalk A.F. \& Moreno G. 1973. Nocardiose: um caso em cão. Arqs Inst. Biológico, São Paulo, 40(1):79-83.

Fawi M.T., Tag El Din M.T. \& El-Sanousi S.M. 1971. Canine distemper as a predisposing factor for Nocardia asteroides infection in the dog. Vet. Rec. 88(13):326-328.

Fighera R.A., Souza T.M., Silva M.C., Brum J.S., Graça D.L., Kommers G.D., Irigoyen L.F. \& Barros C.S.L. 2008. Causas de morte e razões para eutanásia de cães da Mesorregião do Centro Ocidental RioGrandense (19652004). Pesq. Vet. Bras. 28(4):223-230.

Frade M.T.S., Melo L.F., Pessoa C.R.M., Araújo J.L., Fighera R.A., Souza A.P., Uzal F. \& Dantas A.F.M. 2015a. Systemic acanthamoebiasis associated with canine distemper in dogs in the semiarid region of Paraíba, Brazil. Pesq. Vet. Bras. 35(2):160-164.

Frade M.T.S., Maia L.A., Andrade R.L.F.S., Alves R.C., Yamasaki E.M., Mota R.A. \& Dantas A.F.M. 2015b. Clinical, pathological, and immunohistochemistry characterization of toxoplasmosis in dogs with distemper in the semiarid region of Paraíba, Brazil. Semina, Ciênc. Agrárias 36(6): 4251-4256.

Hargis A.M. \& Ginn P.E. 2013. 0 tegumento, p.975-1087. In: McGavin M.D. \& Zachary J.F. (Eds), Bases da Patologia em Veterinária. 5a ed. Elsevier, Brasil. 1324p.

Hilligas J., Van Wie E., Barr J., Russell K. E., Perry A. L., Weeks B.R. \& Zhang S. 2014. Vertebral Osteomyelitis and Multiple Cutaneous Lesions in a Dog Caused by Nocardia pseudobrasiliensis. J. Vet. Intern. Med. 28(5):16211625.

Kinch D.A. 1968. A rapidly fatal infection caused by Nocardia caviae in a dog. J. Pathol. Bacteriol. 95(2):540-546.

Kirpensteijn J. \& Fingland R.B. 1992. Cutaneous actinomycosis and nocardiosis in dogs: 48 cases (1980-1990). J. Am. Vet. Med. Assoc. 201(6):917-920.

MacNeill A.L., Steeil J.C., Dossin O., Hoien-Dalen P.S. \& Maddox C.W. 2010. Disseminated nocardiosis caused by Nocardia abscessus in a dog. Vet. Clin. Pathol.39(3):381-385.

Marino D.J. \& Jaggy A. 1993. Nocardiosis. J. Vet. Intern. Med. 7(1):4-11.

Raskin R.E. \& Meyer D. J. 2011. Citologia de Cães e Gatos: atlas colorido e guia de interpretação. $2^{\text {a }}$ ed. Elsevier, Brasil. 450p.

Ribeiro M.G. \& Condas L.A. 2016. Enfermidades pelo gênero Nocardia, p.199-211. In: Megid J., Ribeiro M.G. \& Paes A.C. (Eds), Doenças Infecciosas em Animais de Produção e de Companhia. Roca, Brasil.

Ribeiro M., Aguiar D.D., Paes A., Megid J., Giuffrida R., Nardi Junior G.D., Moretti L.D. \& Ueno T. 2002. Nocardiose cutânea associada à cinomose em cães: relato de dez casos. Revta Clín. Vet. 39(7):34-42.

Ribeiro M.G., Salerno T., Mattos-Guaraldi A.L.D., Camello T.C.F., Langoni H., Siqueira A.K., Paes A.C., Fernandes M.C. \& Lara G.H.B. 2008. Nocardiosis: an overview and additional report of 28 cases in cattle and dogs. Revta Inst. Med. Trop. S. Paulo. 50(3):177-185.

Silva M.C., Fighera R.A., Brum J.S., Graça D.L., Kommers G.D., Irigoyen L.F. \& Barros C.S.L. 2007. Aspectos clinicopatológicos de 620 casos neurológicos de cinomose em cães. Pesq. Vet. Bras. 27(5):215-220.

Smith P.M., Haughland S.P. \& Jeffery N.D. 2007. Brain abscess in a dog immunosuppressed using cyclosporin. Vet. J.173(3):675-678.

Sykes J.E. 2015. Actinomicose e Nocardiose, p.510-521. In: Greene C.E. (Ed.), Doenças Infecciosas em Cães e Gatos. 4aa ed. Guanabara Koogan, Brasil.

Tizard I. 2014. Imunologia Veterinária. 9aa ed. Elsevier, Brasil. 551p. 